\title{
Balancing Openness and Interpretation in Active Listening
}

Joseph Topornycky and Shaya Golparian University of British Columbia

Active listening is an important communication skill in a variety of disciplines and professions, including the profession of Educational Development. In our roles as educational developers, we engage in a variety of processes, all of which rely heavily on the practice of active listening. Emerging strategies of active listening praxis have allowed us to highlight the risks involved in applying techniques of active listening while engaging in our day to day practices as educational developers. In this paper, we share a short historical review of theories and approaches to active listening and identify its two inherent orientations: humanism and professionalism. We highlight openness and interpretation as two pillars of active listening and explore ways of maintaining a balance between those pillars as they relate to techniques of humanism and professionalism. We explain aspects of the interactive session we facilitated during STLHE 2015 where, as a group, we named and discussed ways that active listening could go wrong. We explore ways that we, as educators and educational developers, might recognize when we may be foregrounding technique over listening, and how to correct some of these issues.

\section{Introduction}

As educational developers we engage in Iconsultation, needs assessment, workshop and program design and facilitation, program coordination, program evaluation, and a variety of other processes, all of which rely heavily on the practice of active listening. There has been extensive attention paid to approaches, strategies, and frameworks for active listening across many professions and disciplines. These strategies can and do help educational developers to attend to the needs of the instructors and teaching assistants (TAs) that they support. However, we have also noticed that these frameworks and approaches can be misused in ways that contravene the intention of active listening.

We have observed firsthand a number of ways that active listening can go wrong in the work of educational developers, particularly when the framework or technique used is foregrounded ahead of the actual act of listening. For example, educational developers may use structured questioning techniques to direct conversation in a way that accords with their own agendas over the expressed needs of the faculty member or graduate student, especially during consultation meetings or instances where educational developers, armed with a repertoire of question and response stems (such as: "I hear you saying ..."), become little more than note-takers for faculty members who are looking for advice or suggestions. Having identified this major challenge in our line of work, we designed and led an interactive session at STLHE 2015, intended for those whose professional educational praxis rely on active listening (i.e. educational developers, instructors, university management). Additionally, our goal was to have participants generate a few strategies for finding an appropriate ethical and practical balance between self and other when actively listening.

In this paper, we investigate active listening as a humanistic and professional practice among educators and educational developers, we share the theory underlying the approach we used during the interactive session on active listening that we 
facilitated at STLHE 2015, and reflect on the outcomes of that session and the implications for active listening.

\section{What We Mean by Active Listening}

Active listening (also called empathic listening, speaker-listener technique, reflected listening, dialogic listening) is the act of hearing a speaker, avoiding premature judgment, reflecting understanding, clarifying information through restating a paraphrased version of the speaker's message and asking questions, summarizing, and sharing (Hoppe, 2006; Weger, Castle Bell, Minei, \& Robinson, 2014). Active listening was first articulated as a formal practice by Gordon (1975) in his Parent Effectiveness Training (P.E.T.) model, and has roots in Rogers's (1951) conceptualization of empathic listening as a condition for humanization of interpersonal relations. Rogers identified three necessary and sufficient conditions for the humanization of any interpersonal relations: (1) value free, positive acceptance of the person talking, (2) active empathetic listening, and (3) congruent (i.e. adequate genuine, and sincere) self-expression in communication with that person (Orlov, 1992). Rogers formulated empathic listening as a psychotherapeutic technique, which demonstrates unconditional acceptance and unbiased reflection of a client's experience through message paraphrasing. This technique of active listening is a part of Rogers's larger humanistic framework, which takes as its operating principle a belief in the importance of human beings as rational, aware, choice-making, goal-seeking, and ecologically integrated with the earth and each other. Rogers firmly believes that interactions with other human beings should always operate with these principles at their foundation. In this paper, we refer to this approach as humanism.

Weger et al. (2014) identify active listening as a therapeutic micro-skill involving "listening attentively and responding empathically so a client feels heard" (p. 14). It is considered a critical communication skill in administration, leadership, and management, as well as in a variety of occupational and therapeutic fields (Bonet, 2001;
Hoppe, 2006; Slizewski, 1995; Weger et al., 2014). Practitioners and researchers from a variety of fields, such as nursing (Bryant, 2009), social work (Rogers \& Welch, 2009), public administration (Stein, 2009), sales (Boe, 2008), physician-patient communication (Fassaert, van Dulmen, Schellevis, \& Bensing, 2007), crisis negotiation (Royce, 2005), leadership (Hoppe, 2007), and education (McNaughton, Hamlin, McCarthy, Head-Reeves, \& Schreiner, 2007) specifically identify active listening as an important communication skill during initial interactions.

The value of active listening across these disciplines and professions is often related to its many practical applications. Active listening can be used to hear accurately, understand, draw out ideas and information, empathize, gather information, show respect, build self-esteem, find answers, show appreciation, buy time, connect, question assumptions and ideas, weigh options, change perspectives, soothe or heal, set the stage for something else, and build relationships (Hoppe, 2006). Listening produces positive interaction outcomes (Weger et al., 2014). Bodie, Worthington, and Imhof (2008) identify understanding, experiencing positive affect, and relationship building as essential products of the listening process.

In most disciplines that have identified active listening as an essential practice, five key techniques of active listening have been identified:

1. Paying attention - This is done by maintaining eye contact with the speaker, putting aside distracting thoughts, avoiding formulating responses while listening, avoiding distractions, and listening to the speaker's body language.

2. Showing that you are listening - This is done by occasionally nodding, smiling, having an open and inviting posture, and encouraging the speaker with small verbal comments such as "yes", "uh huh", etc.

3. Providing feedback - This involves reflection, clarification of the listener's assumptions, and confirmation of our understanding of what was said. This is done through asking 
clarification questions, paraphrasing, and providing a summary of what was said.

4. Deferring judgment - This means allowing the speaker to communicate without interruption, letting them finish each point before asking questions, and refraining from interrupting them with counter arguments.

5. Responding appropriately - This means responding openly and honestly, and treating the other person in a way that we think they would want to be treated.

Particular listening behaviours associated with each technique (mentioned above) have been linked with different attributes. For example, paraphrasing is linked with responsiveness and attentiveness, questioning for clarification has been linked with conversation management as well as responsiveness and attentiveness, and nonverbal behaviours, such as maintaining eye contact, are linked with friendliness, responsiveness, and conversation management (Weger et al., 2014).

We have identified two orientations in our (above) review of the existing literature on the origin and development of active listening as a technique. The first orientation is rooted in Rogers's approach where active listening is a necessary condition of a humanistic approach to interpersonal relations (Orlov, 1992). This situatedness of active listening in humanism means that it is linked, at its essence, with the other two elements of Rogers's humanism: congruence and value-free, positive acceptance of the other person. The second orientation focuses more exclusively on active listening as a professional skill, breaking it down into discrete tasks that are independent of the context and the speaker. It seeks to situate that skill variably within and across different disciplines and professions. The identification of these two orientations framed the development of our understanding of active listening and the development of the session we facilitated at STLHE. In the session, we explored the challenges involved in the focus on active listening as a professional skill, and the value added when active listening remains connected to the larger Rogerian humanistic framework in which it was originally located. The wider humanistic framework supports an ability to find balance between two distinct priorities in active listening: openness and interpretation.

\section{Interpretation and Openness as Two Pillars of Active Listening}

In our engagement with active listening, we found close parallels between active listening and the process of the interpretation of artworks as identified by Barrett (2003), Carroll (2004), and Danto (1983). We found that both active listening and art interpretation involve openness and interpretation as crucial elements in an uneasy balance. Openness, as we are using it here, refers to an immediate attention and receptivity to the formal, and possibly representational properties (e.g. tone, shape, composition, rhythm, texture) of the artwork. Interpretation involves a process of meaning-making which draws upon the art-historical, cultural, and personal context surrounding the artwork. If openness and interpretation are thrown out of balance, we are left either with a mere projection of the viewer/listener that almost entirely ignores the artwork, or else a shallow description of what is immediately present in the artwork itself. This same tension between openness and interpretation exists in active listening. Both elements are essential, and if they are disrupted, we risk erasing the speaker beneath our own projections, or else superficially acknowledging him or her without genuine engagement.

Openness is what we need in order to hear someone else. It is permeability to the thoughts, ideas, feelings, and values of the interlocutor(s), and the listener's ability to hear and remember what is communicated. We could think of openness, at its most extreme, metaphorically as the listener being an audio recorder that faithfully records what a person says, and is able to play back, word-for-word and sound-for-sound, what was spoken. As useful as a recording might be, the device cannot truly be listening, because all it can do is play back what was said, as it was said. We refer to this extreme as parroting. Genuine listening is a human activity that 
requires more than merely taking-in, but must be paired with interpretation to develop understanding.

Understanding is in many ways a much more complex phenomenon, and one that is notoriously difficult to describe. For the purposes of our investigation into active listening, we focused on one aspect of understanding-interpretation. One of the key elements of interpretation is making sense of information you receive by using what you already know to connect and fit it within your existing understanding and view of the world. This integration also invariably changes one's existing understanding and point of view. This connects with the general learning principle that building understanding requires developing connection with prior learning (Ambrose, Bridges, Lovett, Norman, \& Mayer, 2010; Bransford, 2000).

The act of interpretation always carries with it the potential for misinterpretation. While the reasons for a misinterpretation arising are legion, we pay particular attention to misinterpretation arising as a result of projection. This issue can especially arise when, in the attempt to connect new information with prior learning, the new information is, in a sense, overwritten by a person's prior learning, experience, or expectations.

Active listening involves a tension born of two of its component elements. Openness and interpretation are both vital to active listening, but each element can undermine active listening resulting in parroting, where there is receptivity without understanding, or else projection and deletion, where a person's attempt to understand overwrites what was meant to be heard.

Both of these hazards can seriously undermine our work as educational developers. This work builds on initial and ongoing consultations with faculty members, teaching assistants, and graduate students. As educational developers, we are expected to bring our understanding of teaching and learning into the consultations in which we engage, while at the same time, being fully present to the specifics of the context of the person with whom we are working. If we lose our balance between interpretation and openness, we risk projecting our theoretical understanding over the complexity and uniqueness of the teaching and learning context we are meeting in consultation, or else erasing our own insight and understanding of the situation in favor of merely mirroring and validating the other person's concerns and questions back to them.

Interpretation carries an additional risk when in the context of a consultation process. As anyone who is engaged in consultation will realize, those that come to us for support do not always have their ideas, intentions, goals, hopes, and fears fully formed within themselves. When we listen to them, we are not simply receiving a report on those thoughts. Instead, we are often involved in a process of thinking-with, where consultation is a process of not simply reporting, but formulating the question or concern to be addressed in situ. Here is where the process of interpretation on the part of the educational developer can overwrite their interlocutors, not only in the educational developer's mind, but also in the mind of the consulting person.

A person in a state of perplexity may not have fully articulated his or her own question, and, as a result, may experience tension. The educational developer can give a person a way to express something related to the question he or she has, which is not truly an expression of the idea. However, in so doing, they can discharge the tension of perplexity that the person has, such that the person accepts and embraces the educational developer's formulation of the question, idea, or approach as his or her own.

\section{Practices of Active Listening at the Centre for Teaching, Learning, and Technology (CTLT) at the University of British Columbia (UBC)}

Our investigation into active listening was motivated by the many experiences we have had in our educational development work where active listening played a key role. Active listening is used both formally and informally in our work at CTLT at UBC. Informally, active listening is practiced in consultations, program development, and workshop facilitation by many educational developers in our centre. Formally, active listening as a skill has been a major component of the training we have been 
providing in our centre to faculty Peer Reviewers of Teaching since 2006. Faculty peer reviewers meet with reviewees before and after observing their teaching to come to a mutual understanding of where feedback is expected, and provide and discuss feedback based on the classroom observation (Cassidy \& Johnson, 2006; Golparian, Chan, \& Cassidy, 2015). The effectiveness of peer review of teaching relies on the reviewers' ability to identify the needs of the reviewees and offer constructive feedback accordingly, which is why active listening is an important focal point in the Introduction to Peer Review of Teaching Workshop that we offer. The four-hour-long introductory workshop to peer review of teaching engages the participants of the workshop in participatory activities that allow them to practice the techniques of active listening as identified in the literature: paraphrasing, probing and questioning techniques, and the use of appropriate verbal and body languages.

One of the first workshop activities for participants is their role play of a pre-observation meeting in which the reviewer asks for the reviewee's expectation of the peer review of teaching process. This activity is situated in the formative peer review of teaching context, which supports mentorship and professional development, rather than in the summative peer review of teaching context, which is for evaluation (tenure and promotion) purposes. In the role-play activity, the reviewer is instructed to not respond for three minutes while the reviewee figures out their own expectations (of the peer review of teaching process) through speaking. Once the three minutes have elapsed, the reviewer then asks clarification questions and paraphrases the reviewee's words to make sure they have understood what the reviewee expects to gain from this experience.

The objective for this activity is to provide the future reviewers with an opportunity to practice deferring judgment, as well as questioning and paraphrasing techniques. Throughout this four-hourlong workshop, participants draw on these techniques to practice active listening alongside other essential techniques to the role of peer reviewer of teaching.

Besides the obvious incorporation of the techniques of active listening in workshops and sessions that we offer at CTLT, these techniques (particularly questioning and paraphrasing techniques) are also incorporated into facilitation workshops that are offered to TAs and faculty members at UBC. Active listening is identified by many educational developers as one of the most important facilitation skills. In roundtable conversations with experienced educational developers in Canada during the EDC Institute 2013, all of the guest educational developers identified being an active listener as the most important quality a facilitator can possess. As part of the facilitation workshops that we offer in our teaching and learning centre, the participants get multiple opportunities to learn and practice active listening techniques such as paraphrasing, probing, and questioning.

\section{Our Goal for the STLHE Session}

Having facilitated the Introduction to Peer Review of Teaching Workshop many times over the past few years, one of the recurring questions that has occupied our minds is whether or not learning and applying the techniques that have been identified in the literature on active listening guarantee that active listening is really occurring. In the world of educational development, applying these techniques has almost become second nature to us. However, we have also encountered the hazards of projecting and parroting identified above, even in cases where the manner of active listening has been an otherwise exemplary model of best practice.

A specific incident that illustrates this point is related by a colleague describing her work process during a facilitated meeting. The facilitator, while taking notes on flipchart paper, was paraphrasing what our colleague had been describing: "What I hear you say is ...". After the meeting my colleague was quite frustrated, feeling that she was treated as a project. Her exact words were: "Do not facilitate me!" Thinking back to this incident, we realized that the frustration expressed was an objection to the superficial application of identified techniques of active listening. The facilitator seemed to have done everything as suggested in the active listening literature. She maintained eye contact, she did not 
interrupt our colleague, and she paraphrased the statement before capturing it to make sure she did not misinterpret her words. Yet something in that interaction did not feel real or honest to our colleague. She did not feel heard. This particular situation is an example of what we have already identified as parroting, and the impact it can have on the person in need of a listening ear. In the 60 minute interactive session that we facilitated at STLHE 2015, we engaged participants in small group, guided practice, and brainstorming activities to identify unconscious acts of, and the ethical hazards involved in, projecting and parroting during active listening. During this session, participants developed processes of self-monitoring and worked to find an appropriate ethical and practical balance between self and other when actively listening.

\section{Key Elements of the STLHE Session}

We describe below how we involved participants throughout the conference session in participatory activities in order to investigate the risks mentioned above and develop strategies to address those risks. We invite you to modify the elements below for your own use.

\section{Listening as an Act of Interpretation}

We began the session by projecting an image of Picasso's painting, The Old Guitarist, on the wall, and inviting participants to tell us what they saw in the image. Responses ranged from personal reactions to the painting, interpretations of the emotional state of the guitarist, and reflections on the painter, to descriptions that placed the painting in its arthistorical context at the beginning of Picasso's Blue Period. We discussed how each interpretation is a valid interpretation, yet more or less relevant to the artwork and always incomplete. We did this activity to illustrate and discuss the parallel between art interpretation and active listening.

\section{Overview of the Active Listening Skillset Model}

Next, we shifted focus more directly to active listening by asking the participants to brainstorm things they do when actively listening. We shared Hoppe's (2006) model of the Active Listening Skillset as an example of a skills-focused approach to active listening. The model identifies paying attention, holding judgment, reflecting, clarifying, summarizing, and sharing as the skills involved in active listening. We shared with the participants that this exemplifies the professional/skill focused approach to active listening, which frames it as an independent skillset potentially situated across many different kinds of professional practices.

\section{Listening as Crossing Bridges}

The question of finding a balance on the continuum between openness and interpretation was introduced using the metaphor of a bridge, with the speaker and listener representing either side of the bridge. Participants were invited to place themselves where they thought the speaker and listener should meet, using a sticky note. The meeting point would come to represent the balance between openness and interpretation that was the key theme of our session. We invited the participants to discuss the following questions in pairs:

- What does meeting the other person mean?

- What is involved in the speaker moving towards the listener?

- What is involved in the listener moving towards the speaker?

- How do active listening skills help the listener or prevent them from moving towards the speaker?

- How do active listening skills help the speaker or prevent them from moving towards the listener?

Following their conversations, several participants decided to move their sticky notes to another point on the bridge. All participants who decided to do so 
moved the sticky notes they had placed on the bridge closer to the side where the speaker was standing. This activity led to a discussion around context and how it impacts finding the balance in the process of active listening. We also discussed the potential for false compromises being an easy, but ineffective way of finding balance, where two incompatible options are combined into one that is desirable to neither party. There is something temptingly egalitarian and fair about meeting in the middle when considered as a principle. This principle assumes that both parties' interests are reflected in the middle and that there is an equal division of labor in the work of compromise. However, even though sometimes this really is both the best and most fair strategy, the appropriateness of meeting in the middle needs to be determined on a case-by-case basis, informed by context, rather than being assumed as a general rule. Sometimes, the middle is a terrible place. During the session we used the metaphor of sardine-chocolate cake to describe a meal that pretends to meet the needs of two different parties, but satisfies no one.

\section{The Ethical Hazard of Projecting and Parroting}

The next activity focused on analyzing a pair of case studies that showed some of the problems that might occur when openness and interpretation are not balanced. One of the cases involved an instructor making problematic claims about their students and the educational developer mirroring those without probing or challenging. The other case involved the educational developer suggesting solutions emerging from their own values that were not necessarily relevant to the problem being described by the instructor. Participants discussed each of these cases in pairs and then we debriefed the activity in the large group. Based on these case studies, we discussed what might cause an educational developer or instructor to encounter these kinds of challenges, and what approaches or strategies they might take to address them.

\section{Strategies to Prevent Parroting and Projecting}

We engaged the participants in an open discussion around strategies they can use as educators or educational developers to minimize the risks of parroting and projecting. Some of the strategies we discussed and/or shared with the participants include: being attentive to expert blind spots; avoiding quick responses; questioning our own understanding; being attentive to the affective elements of the consultation; trying to set aside or deprioritize our own agendas in favour of the person speaking; and framing clarification questions in ways that are less suggestive.

Many of the above strategies attempt to correct one extreme by introducing the elements of the other. For example, attention to expert blind spots cautions us against projecting our own understanding onto the situation by problematizing expertise as a potential blind spot. The actual point of balance between the two extremes is highly contextually determined. What is an appropriate balance in one case may be entirely inappropriate in another. Therefore, we cannot settle easily on a universal rule for finding this balance, but must constantly reexamine our practices and our positions between the two pillars of openness and interpretation. It is otherwise too easy to flip from one extreme to the other.

\section{Session Reflections}

One of the key lessons we learned from the development and delivery of this session is that there is no easy formula for finding the perfect balance between openness and interpretation in active listening. True to its roots in the works of Carl Rogers, we found that active listening is at its core a humanistic activity which is subject to harm by being too structured or bound up in a role. A role is always, at best, only partially human, and the borders of our roles come by mostly subtracting or suppressing elements of our full identity. We need humanity to calibrate and maintain the difficult balance between openness and interpretation. One of the greatest risks 
to upsetting that delicate balance is entering into the act of listening as a kind of professional practice. Our discussions prior to and during the STLHE session suggest that the professionalization of listening risks splitting technique away from the context which grounds its authenticity.

We can best find that balance by first and foremost striving to listen and really hear what another person is saying as opposed to "responding empathically so a client feels heard" (Weger et al., 2014, p. 14, emphasis added). The prescribed practices of active listening are simply a description of the outward behaviours, and in some cases the general attitudes of a person who listens well. We can use these descriptions to imitate good listening, and through imitation, improve our practice (just as Aristotle tells us). However, the act of listening requires us to avoid imitation and instead rely on our humanity in order to strike a balance between openness and interpretation-it is this humanistic approach that allows us to appropriately respond to those who speak to us. Active listening is an act of care-an outward display of genuine interest in what another person has to say.

\section{Next Steps}

Having investigated the risks involved in taking a skills-based approach to active listening, we move forward with caution in our practices as educational developers. We are committed to ongoing assessment of our engagement with those that come to us for help in order to avoid projecting or parroting.

We have plans to offer sessions similar to the one we led at STLHE 2015-in our centre and in other venues_as a way to engage colleagues in conversations around the balance between openness and interpretation. We believe that such conversations, as highlighted in the literature on active listening, would be beneficial to practitioners in variety of disciplines, and particularly in a university setting.

\section{References}

Ambrose, S. A., Bridges, M. W., DiPietro, M, Lovett, M. C., Norman, M. K., Mayer, R. E. (2010). How learning works: Seven research-based principles for smart teaching. San Francisco, CA: Jossey-Bass.

Barrett, T. (2003). Interpreting art: Reflecting, wondering, and responding. Boston: McGraw-Hill.

Bodie, G. D., Worthington, D., Imhof, M., \& Cooper, L. O. (2008). What would a unified field of listening look like? A proposal linking past perspectives and future endeavors. International Journal of Listening, 22(2), 103122. http://dx.doi.org/10.1080/109040108 02174867 VIEW ITEM

Boe, J. (2008). How to build trust \& rapport quickly. American Salesman, 53(10), 15-18.

Bonet, D. (2001). The business of listening: A practical guide to effective listening. Menlo Park, CA: Crisp Learning.

Bransford, J. (2000). How people learn: Brain, mind, experience, and school. Washington, D.C: National Academy Press. http://dx.doi.org/1 0.17226/9853 VIEW ITEM

Bryant, L. (2009). The art of active listening. Practice Nurse, 37(6), 49-52.

Carroll, N. (2004). Non-perceptual aesthetic properties. British Journal of Aesthetics, 44, 413-423. http://dx.doi.org/10.1093/bjaesth etics/44.4.413 VIEW ITEM

Danto, A. (1983). The transfiguration of the commonplace. Cambridge: Harvard University Press.

Cassidy, A., \& Johnson, J. (2006). Developing your skills as a peer reviewer: Introductory workshop 
handbook. Centre for Teaching and Academic Growth. University of British Columbia. Retrieved from http://wiki.ubc.ca /images/2/23/PRWkshpHdbk(2016_02).pd f VIEW ITEM

Fassaert, T., van Dulmen, S., Schellevis, F., \& Bensing, J. (2007). Active listening in medical consultations: Development of the Active Listening Observation Scale (ALOSglobal). Patient Education \& Counseling, 68, 258-264. https://dx.doi.org/10.1016/j.pec.2 007.06.011 VIEW ITEM

Golparian, S., Chan, J., \& Cassidy, A. (2015). Peer review of teaching: sharing best practices. Collected Essays on Teaching and Learning, 8, 211-218. Retrieved from http://celt.uwindso r.ca/ojs/leddy/index.php/CELT/article/view /4239 VIEW ITEM

Gordon, T. (1975). P.E.T.: Parent effectiveness training. New York, NY: New American Library.

Hoppe, M. H. (2007). Lending an ear: Why leaders must learn to listen actively. Leadership in Action, 27(4), 11-14.

Hoppe, M. H. (2006). Active listening: Improve your ability to listen and lead. Greensboro, N.C: Center for Creative Leadership.

McNaughton, D., Hamlin, D., McCarthy, J., HeadReeves, D., \& Schreiner, M. (2007). Learning to listen: Teaching an active listening strategy to pre-service education professionals. Topics in Early Childhood Special Education, 27, 223-231. http://dx.doi .org/10.1177/0271121407311241 VIEW ITEM

Orlov, A. B. (1992). Carl Rogers and contemporary humanism. Journal of Russian and East European Psychology, 30(1), 36-41. http://dx.doi.org/10.2753/RPO1061-0405 300136 VIEW ITEM
Rogers, A., \& Welch, B. (2009). Using standardized clients in the classroom: An evaluation of a training module to teach active listening skills to social work students. Journal of Teaching in Social Work, 29, 153-168. http://dx.doi.org/10.1080/0884123080223 8203 VIEW ITEM

Rogers, C. R. (1951). Client-centered therapy. Boston, MA: Houghton-Mifflin.

Royce, T. (2005). The negotiator and the bomber: Analyzing the critical role of active listening in crisis negotiations. Negotiation Journal, 21(1), 5-27. https://dx.doi.org/10.1111/j. 1571-9979.2005.00045.x VIEW ITEM

Slizewski, P. (1995). Tips for active listening. $H R$ Focus, $72(5), 7$.

Stein, D. (2009). Reducing audience aggression by reflecting back. Public Management, 91, 34.

Weger, H., Castle Bell, G., Minei, E. M., \& Robinson, M. C. (2014). The relative effectiveness of active listening in initial interactions. International Journal of Listening, 28, 13-31. http://dx.doi.org/10.10 80/10904018.2013.813234 VIEW ITEM

\section{Acknowledgements}

We would like to thank Dr. Isabeau Iqbal, whose comments and suggestions helped us to improve this paper. We are grateful to the editors and organizers of CELT for their hard work on this publication.

\section{Biographies}

Joseph Topornycky, Ph.D. is an Educational Developer and the Manager of Graduate Student Programs at the Centre for Teaching, Learning, and Technology (CTLT) at the University of British 
Columbia (UBC). Joseph designs and develops CTLT's overall programming and support for graduate students and teaching assistants. Joseph works with his team to ensure that graduate student support is informed by current research on how people learn and well-grounded teaching and learning theory. He is also the lead developer and facilitator for the certificate in advanced pedagogy for graduate students.

Shaya Golparian, Ph.D. is an Educational Developer at the Centre for Teaching, Learning, and Technology (CTLT) at the University of British Columbia (UBC). She is involved with various teaching and learning professional development projects and initiatives. Shaya develops and coordinates the TA Development Program and consults with department and faculty representatives to plan, design, and deliver department-specific TA teaching skills development programs and workshops. 